\title{
Innovating for student success: The University Leadership Network (ULN) and tiered undergraduate peer mentor model
}

Jennifer L. Smith, PhD

\begin{abstract}
This paper highlights the innovative approach the Student Success Initiative's unit at the University of Texas at Austin is taking to increase undergraduate persistence and four-year graduation rates. Specifically, this piece explores the large-scale University Leadership Network (ULN) program and examines the tiered undergraduate peer mentor model utilized to support the success of first-year students from low-socioeconomic backgrounds, including a majority of underrepresented minority (URM) students. The article also reviews the critical role peer mentors play in helping to meet institution-wide goals and how they extend the reach of student support programs. Lastly, best practices, challenges, and components necessary for program replication will be presented.
\end{abstract}

\section{Keywords}

Peer mentor, training, underrepresented students

\section{Introduction}

The role of the undergraduate peer mentor serves as a substantial source of positive influence on fellow college students' level of engagement and academic and nonacademic success. According to Astin (1993), "The student's peer group is the single most potent source of influence on growth and development during the undergraduate years" (p. 398). Additionally, the role of the peer mentor has gone through an extensive evolution throughout the history of higher education. The role has progressed from offering primarily low-level clerical support to university staff, to tutoring, to now acting in the critical role of peer mentor to support undergraduate student success (Hansen \& Johnston, 1986).

Peer mentor programs demonstrate the strength of the peer influence and ability to perform the mentor role because of institutional investment in quality supervision and training (Sipe, 1996). This preparation, and the benefit of having more student paraprofessionals, extend the ability for an organization and institution to meet student success objectives. For example, peer mentors have the ability to meet with students with more frequency and thereby build rapport, creating an environment where student community can flourish. Creating a sense of belonging encourages mentees to share more openly about successes and challenges, in turn fostering opportunity for mentors to provide guidance and resources, which promote student success. Overall, a peer mentor program with clear structure and purpose, quality training, and institutional support can greatly increase student persistence and ultimately graduation rates (Coles, 2011). 
The University of Texas at Austin (UT Austin) is taking great strides to provide academic, cocurricular programming, and financial support for all students, including the increasing number of underrepresented minority (URM) students. For the purposes of this article, URM students include African American, Hispanic, low-income, and first-generation college students. Current research strongly shapes efforts to increase student success at UT Austin. The institution carefully examines student outcomes of low-income and first-generation students, in addition to URM groups and their performance at predominantly white institutions (PWI) in relation to Historically Black Colleges and Universities (HBCUs) and Hispanic Serving Institutions (HSIs) (Allen, 1992; Cokely, 2000; Flowers, 2002; Harris, 2012). This area of research provides insight into creating academic and co-curricular atmospheres that create community and opportunity for success for URM students.

Research indicates low-income and first-generation students are at increased risk of failure in post-secondary education, due to a variety of contributing factors, such as academic preparation, demographic backgrounds, and other conditions. (Walpole, 2003). Engle and Tinto (2008) suggest, "The problem is as much the result of the experiences students have during college as it is attributable to the experiences they have before they enroll” (p.3). Their research demonstrates that low-income, first-generation students are also less likely to engage in activities that foster success, resulting in "lower levels of academic and social integration [which]...are inextricably linked to finances and financial aid" (p.3). Engle and Tinto go on to state that universities wishing to see an increase in success for low-income and first-generation students should provide additional financial aid and create structured programs and initiatives to ease the transition from high school to college. The University of Texas at Austin's response to this research has resulted in the expansion of existing and creation of new student success initiatives.

Regarding URM populations, UT Austin also examines the idea of academic self-concept. The "best predictor of academic self-concept for students attending HBCUs was quality of studentfaculty interactions, [while] grade point average is significantly more important for the academic self-concept of African American students attending [PWIs] than African American students attending HBCUs" (Cokely, 2000, p.1). UT Austin is categorized as a PWI, with $44 \%$ of the student body identified as White (The University of Texas Statistical Handbook, 2015). The literature also confirms that URM students exhibit reduced levels of academic success due to a range of pre-college factors, such as lower levels of parental or guardian education, academic preparedness, socioeconomic status, and ascribing to racial stereotypes propagated through media and other social constructs (Allen, 1985; Fry, 2011; Strayhorn \& Terrell, 2010).

Researchers seek to further understand the lived experiences of URM students attending PWIs. For example, Dalhvig (2010) and Strayhorn \& Terrell (2010) reported that African American and Latino students describe their experiences on PWI campuses as "chilly" and "restrictive." URM students and males in particular are not only seeking to acclimate to university life at a PWI where they may already feel isolated, but also report having to combat stereotypes as they are perceived as "threatening, unfriendly, and less intelligent" (Cuyjet, 1997, p. 8). The tailored experiences that HBCUs and HSIs provide for URM students leads to increased academic success, student satisfaction, and development of student leadership opportunities (Allen, 1992; Fleming, 1984; Flowers \& Pascarella, 1999). Reddick (2006) suggests that PWIs should "seek the assistance of historically Black colleges and universities if these organizations truly desire to 
support African-American students” (p. 15). More than 85\% of African-American students enroll at PWIs, and demographic forecasting indicates that the Hispanic population will become the largest ethnic group in higher education in the near future (Fry, 2011, Reddick, 2006). It is clear that PWIs need to determine how to create conducive learning environments for URM students. UT Austin is actively working to create and implement innovative programming for URM students, designed to provide a holistic experience during their four years that includes academic and financial support, opportunities to develop professional and leadership skills, and peer mentoring.

The University Leadership Network (ULN) is the largest student success initiative at The University of Texas at Austin (UT Austin), designed to support first-time-in-college (FTIC) students from low-socioeconomic backgrounds (annual family income less than \$60,000). One byproduct of serving low-income students is that $67.2 \%$ of the students are from underrepresented groups and $67.8 \%$ are also the first in their families to attend college (ULN Brochure, 2016). One of the most critical components of the program model is peer mentoring. ULN has created a peer mentor model that shifts the role of the peer mentor relationship from solely academic success to one of long-term leadership and professional development. Recognized as a pioneering incentive-based graduation program, ULN's program model has a focus on leadership, professional development, and experiential learning. These efforts have received national recognition in publications such as Paul Tough's (2014) article, "Who gets to graduate" in the May issue of the New York Times Magazine, and were featured on PBS NewsHour in the summer of 2015 ("Why Poor Students Drop out Even When Financial Aid Covers the Cost," August 17, 2015). This recognition has created excitement around student success and collaborative efforts to share best practices of the model.

This article provides an overview of UT Austin as an institution, the ULN program as a whole, and a thorough review of the ULN peer mentor model. The following section will provide an indepth analysis examining why the ULN peer mentor model is ideal for increasing student success and present lessons learned through program implementation. Lastly, this piece concludes with an outline of program and institutional components necessary for program replication and future vision for ULN.

\section{Background}

The University of Texas at Austin (UT Austin) is a four-year, full-time, more selective, public institution with highest research activity. (Carnegie Foundation, 2015). UT Austin was founded in 1882 and contains 18 colleges and schools. The student population is served by 3,090 faculty and thousands of staff members. UT Austin as of 2015 has a student body of 50,950, with an undergraduate population of 39,619 students; (The University of Texas Statistical Handbook, 2015). UT Austin is also ranked $14^{\text {th }}$ most innovative school and $18^{\text {th }}$ among top public institutions (U.S. News \& World Report, 2016).

As of fall 2015, UT Austin's undergraduate population is 44.4\% White, 22.1\% Hispanic, 4.9\% Black, 19.9\% Asian, .2\% American Indian, .1\% Hawaiian/Pacific Islander, 2.9\% Multi-Racial (2 or more, excluding Hispanic and Black), 4.9\% Foreign, and .7\% Unknown. Although our Hispanic population is growing, our Black population has not yet risen above 5\%. Within the 
2015 undergraduate student population there are 19,016 males (48\%) and 20,603 (52\%) females (The University of Texas Statistical Handbook, 2015). UT Austin is the flagship institution within the state of Texas and is held up as a model for the state and the nation for creating and implementing innovative programs like the ULN in order to increase undergraduate student success. One indicator of this success appears in UT Austin's participation in the University Innovations Alliance (UIA). UT Austin collaborates with a group of ten peer institutions focused on identifying and implementing innovative student success initiatives. This work was featured in a recent Inside Higher Ed piece, "Officials at 11 Partnering Institutions Share Strategies for Helping Students Graduate,” (Thomsen, J. 2015). ULN staff presented the program and mentor model when UT Austin hosted the UIA representatives earlier in the year.

\section{History}

The creation of the ULN was made possible by a dramatic change in how UT Austin defines and prioritizes student success. The institutional culture shifted in response to an ambitious and publicly declared goal to increase the university's four-year graduation rate to $70 \%$ by 2017 . In 2011, when the goal was set by then-UT Austin President Bill Powers, the university's four-year graduation rate was $51 \%$ for its roughly 40,000 undergraduates. Though this rate was the highest among public colleges and universities in Texas, it was well below four-year graduation rates at some peer institutions like the University of Michigan at Ann Arbor and the University of North Carolina at Chapel Hill (National Center for Education Statistics). Focusing on four-year graduation as a top priority was supported at the statewide level as well. was The University of Texas System leadership touted the 70\% goal as an important step in the efforts of its institutions to improve graduation rates, persistence rates and the number of degrees conferred, as part of their commitment to make higher education more accessible to a greater number of students (Cigarroa, 2011). Targeting graduation rates as a focus for improvement also reflected the growing national concern over accessibility and affordability in college education when career and earning outcomes are increasingly tied to degree completion (Baum, Ma, \& Payea, 2013; The White House Office of the Press Secretary, 2009).

The mandate to raise graduation rates initiated a focal point for campus-wide efforts and provided unprecedented resources to create and scale up student success initiatives. To lead these efforts, the position of Senior Vice Provost of Enrollment and Graduation Management was created to be the "Graduation Rate Champion." This new leadership role was designed to bring together campus units across the undergraduate experience- admissions, financial aid, registrar, academic colleges, advisors, technology and facilities - toward the common goal of supporting student progress toward four-year graduation (UT News, 2012). David Laude, UT Austin's Senior Vice Provost for Enrollment and Curriculum and Graduation Rate Champion, continues to teach undergraduate students as a professor of chemistry and also brings many years of previous experience creating effective programs for student success in UT Austin's College of Natural Sciences. To support the bold initiatives required for a leap forward in on-time graduation, the Provost's Office designated yearly funds to provide for student success initiatives university-wide. The amount calculated to approximately $\$ 100$ per undergraduate per year, a moderate sum that has brought about sizable improvements in student success metrics like persistence and graduation rates. Leveraging existing practices and current staff in creative ways to implement innovative changes enabled a cost-effective transformation. 
Since the 70\% graduation rate goal was set in place, the Graduation Rate Champion has led a number of large-scale projects designed to support student success, impacting thousands of students yearly. UT Austin created a Student Success Initiatives team to implement and oversee these projects, working with numerous academic and co-curricular units across campus. Some initiatives impacted institutional processes like advising and student tracking; these activities now include data-driven predictive analytics used to identify students likely to benefit from extra support through success programs or strategic advising. Others focused on the first-year undergraduate experience: all first-years at UT Austin now take part in a redesigned orientation experience, emphasizing academic expectations, and participate in small learning communities during their first semester. Academic learning communities that apply research-based practices to support student success already existed on campus, but were expanded to support 25\% of all freshmen, focusing on those identified as most likely to benefit from additional support to graduate on time based on predictive analytics. Many of the improved programs and processes initiated by the push for improved success operate broadly and affect all UT Austin undergraduates, but the most innovative is the University Leadership Network, a student program designed to remove non-academic barriers to success for those students who arrive at college with high financial need and less likelihood of graduating on time.

Since the four-year graduation rate goal was set in 2011, the graduation rate has risen by ten percentage points to $61 \%$ for students graduating in 2016, the university's highest four-year graduation rate on record (The University of Texas Statistical Handbook, 2016). The first-year persistence rate at UT Austin rose from 91.8\% in 2011 to a new high of $94.5 \%$ for students returning in 2014. Furthermore, the most recent cohort of first-years achieved a $95.1 \%$ persistence rate in 2016. In 2016, moreover, institutional records were achieved by juniors and seniors as well. Persistence after the second year reached a high of $91.9 \%$ for students returning as juniors, and the class returning as seniors raised the bar with $85.2 \%$ persisting. Setting the lofty goal for a $70 \%$ four-year graduation rate in five years catalyzed a transformation in student success at UT Austin that is making a difference for students and for the institution.

\section{Program description}

The University Leadership Network (ULN) program at UT Austin is an undergraduate incentivebased scholarship program focused upon developing professional and leadership skills while achieving academic success that is consistent with graduating in four years. The ULN student population consists of students with demonstrated financial need and who have generally come from under-resourced high schools in Texas.

ULN's mission is "to encourage and support students to graduate in four years and become leaders through professional and experiential learning opportunities that advance their education, communities, and lives” (ULN, 2015).

Across the ULN classes of 2017, 2018, and 2019 the average combined household income of ULN students is less than $\$ 60,000$ per year. Additionally, ULN serves a large number of URM students. Across the previously mentioned three cohorts, $67.2 \%$ of ULN students come from 
underrepresented groups and $67.8 \%$ are also first-generation college students. All ULN students enter the program as first-time in college students and are selected from across all majors and colleges. Each entering class consists of 500 students.

As of fall 2016, ULN serves up to 2000 students, with up to 500 students in each cohort (freshman, sophomore, junior, and senior). Participating students earn an annual scholarship of $\$ 5,000$, which is disbursed in monthly increments of \$500 throughout the fall and spring semesters as program requirements are met. Students who participate all four years in the University Leadership Network earn up to $\$ 20,000$ in scholarship funds, which also leads to a decreased student debt-load. The initial funding for the ULN program arose out of a onetime gift provided by the University of Texas Board of Regents in 2013. When that funding had been utilized, the scholarships shifted to utilizing tuition set-aside funds. Tuition set-aside funds operate by a formula, in which a percentage of every tuition dollar is set aside to be utilized for students qualifying for need-based financial aid. The external relations team within the Provost's Office has cultivated relationships to fund scholarship, program, and operational costs. The Houston Endowment gave a significant gift of \$8.2 million dollars to support three full cohorts of 125 students from the Houston Area and to fund a quarter of the program's operational costs in the fall of 2015. The remaining funding for operational costs is provided through the Provost's Office, as the program is a part of the Student Success Initiatives unit housed within the Provost's Office.

All ULN students participate in first-year academic learning communities in addition to their participation in ULN. Expansion funds provided by the Student Success Initiatives has made it possible for all ULN students to participate in existing successful first-year academic learning programs across colleges and units. The academic learning communities meet with students during orientation. During the academic year, they provide individual advising, access to no-cost tutoring and collaborative study, guidance from academic peer mentors throughout their first year, and access to sought-after and/or smaller classes. This partnership ensures that first-year students in ULN have a firm academic foundation in addition to four years of leadership and professional development opportunities and guidance from the ULN team. The directors and team members maintain collaboration across the leadership of academic learning communities, ULN, and Student Success Initiatives by meeting weekly to discuss ongoing initiatives, address challenges and changes, and to discuss new initiatives or resources that benefit student success.

ULN students have a campus reputation for their notable authentic leadership, professionalism, and grit. From their first day, ULN Students experience a culture dedicated to helping them learn to lead from where they are. Participants begin their foundational year by attending the weekly Leadership Speaker Series and small group meetings facilitated by their ULN Peer Mentors. In the second year, students participate in exciting on-campus internships with campus partners from diverse units/departments across the university. During their third and fourth years, ULN students engage in more tailored experiential learning opportunities such as study abroad, research, on/off-campus internships, or Project-Lead (non-profit project management program). Graduating seniors present their four-year ULN experience in group or individual presentations during the Fall Leadership Showcase and conclude their final semester attending "Next Steps" programming events designed to ensure students are prepared for post-graduate lives in industry, graduate or professional education, and beyond. In addition to experiential learning, ULN 
program requirements include: (a) completing 5-10 hours of community service per semester in the UT/Austin community; (b) engaging in self-reflection; (c) completing 25\% of hours needed for their individual degree plan each academic cycle (fall, spring, summer); and (d) to remain in good academic standing (2.0-4.0 GPA) with the institution. The following sections focus on describing the ULN peer mentor population, program, and training structure, and the unique shift from traditional peer mentoring to professional development coaching for underrepresented students with demonstrated financial need.

\section{ULN peer mentor population}

ULN peer mentors focus on serving as professional development coaches to first-year students in the program. Our year-two coordinator also serves as the coordinator and supervisor for all ULN mentors. The ULN staff member facilitates training sessions, organizes detailed logistical aspects of the program and leads weekly training for lead mentors. ULN peer mentors lead weekly small group discussion sections designed to allow our first-year students to apply and reflect on topics presented in their weekly leadership speaker series. Reflection can involve small group discussion, individual journal reflections, etc. Each peer mentor strives to develop the professional skills of first-year students and create a supportive community-centered environment.

Table 1.

Selected Characteristics of ULN Peer Mentors

\begin{tabular}{|c|c|}
\hline \multicolumn{2}{|c|}{$\begin{array}{l}2015 \text { - } 16 \\
\text { ULN Peer Mentor } \\
\text { Demographics }\end{array}$} \\
\hline Asian & 12 \\
\hline Black & 6 \\
\hline Hispanic & 47 \\
\hline White & 6 \\
\hline Foreign & 4 \\
\hline Multiracial & 1 \\
\hline $\begin{array}{l}\text { Not } \\
\text { Reported }\end{array}$ & 1 \\
\hline Total & 75 \\
\hline
\end{tabular}

\begin{tabular}{|l|l|}
\hline $\begin{array}{l}\text { 2015-16 ULN Peer Mentor } \\
\text { College Breakdown } \\
\text { Architecture }\end{array}$ & 2 \\
\hline $\begin{array}{l}\text { Business } \\
\text { Administration }\end{array}$ & 3 \\
\hline Communication & 9 \\
\hline Education & 1 \\
\hline Engineering & 13 \\
\hline Fine Arts & 5 \\
\hline Geosciences & 0 \\
\hline Graduate School & 0 \\
\hline Liberal Arts & 12 \\
\hline Natural Sciences & 27 \\
\hline Nursing & 4 \\
\hline Social Work & 0 \\
\hline Undergraduate & 1 \\
\hline Studies & \\
\hline
\end{tabular}

All ULN peer mentors consist of successful second-, third-, and fourth- year ULN students representative of all colleges. Their participation as peer mentors counts as their experiential learning opportunity. Within their peer mentoring experience, students gain valuable transferable 
skills such as: leadership development, organization, interpersonal development, cultural competency, conflict resolution, group dynamics, etc. For the 2015-16 academic year, the ULN peer mentor cohort (see Table 1) consisted of 77 students (58 second-year students, and 19 thirdyear students). Of that group, 24 mentors were male and 53 mentors were female. Their cumulative GPA as a cohort was 2.93. The Lead Mentor cohort consisted of nine students (all third-year students). Within this group, four were male and five were female. Their cumulative GPA as a Lead Mentor cohort was 3.35. As our program serves students from all majors and colleges, our mentor population is also representative of that diversity.

\section{Mentor selection}

Mentor applications are open to all second- through fourth-year ULN students. The recruitment process occurs during the months of February through April. To clarify, peer mentors are not student employees and do not earn an hourly wage. Serving in a mentor role meets their experiential learning requirement in addition to other program requirements (service, academics, etc.) which results in their monthly scholarship disbursement. Mentors are able to review the mentor position description on the online posting system. Then the Mentor Coordinator and a small number of existing Lead and ULN Mentors operate a booth at the spring ULN internship fair. This provides an opportunity for prospective mentors to ask questions regarding the role of a ULN peer mentor and to hear about the experiences and perspectives of current peer mentors.

Following the internship fair, students can submit an online application, resume, and letter of recommendation from a current ULN peer mentor within the online posting system. Prospective mentors are interviewed individually with a ULN staff member and when possible also a current peer mentor. Having a current peer mentor within the recruitment process has proven to be a critical ingredient in the success of our recruitment process. Initiating the desire to hear the student perspective during the process creates a more diverse lens to review the candidates. Typically, 100 to 150 candidates apply for the position to fill up to 80 available positions.

\section{Program model}

The ULN peer mentor model utilizes existing research, a nationally known training model, and the use of a tiered structure of leadership. Although I direct the program, my previous experience as a mentor coordinator (eight years) and research background in the field of mentoring heavily influenced the ULN mentor model as it is today. The sections below examine the theoretical frameworks that support the model, highlight the structure and influence provided by the College Reading and Learning Association (CRLA) International Mentor Training Program Certification (IMTPC) and training model, and lastly a careful look into the tiered structure of leadership within the mentor model.

Mentoring research from the disciplines of Business and Education have greatly influenced the development of the ULN mentor model. Within the field of Business, the concepts of the psychosocial and vocational functions of mentoring are key in understanding the phenomenon. Here the psychosocial function refers to the mentor offering "role modeling, counseling, confirmation, and friendship, which help the young adult to develop a sense of professional identity and confidence” (Kram \& Isabella, 1985, p. 111). The vocational function highlights the 
way mentoring creates an opportunity to provide "sponsorship, coaching, facilitating exposure and visibility, and offering challenging work or protection, all of which help the younger person establish a role in the organization, learn the ropes, and prepare for advancement” (Kram \& Isabella, 1985, p.111). Within higher education there is limited research focused on the experiences of peer mentors. My research explores the experiences of underrepresented undergraduates serving fellow underrepresented first-year students at a predominantly white institution (PWI). Extending upon the work of Moore and Amey (1988), my research introduces a tailored operational definition of undergraduate peer mentoring:

Undergraduate peer mentoring is a relationship between a more experienced undergraduate student from an underrepresented population (typically older) acting as a role model, friend, and resource to a less experienced undergraduate student (typically younger) who is also from an underrepresented population. The aim of the mentoring relationship is to further the mutual development and refinement of both the mentee and mentor's psychosocial and vocational skills in order to aid in their successful transition to college life (Smith, 2014, p. 209).

The definition highlights the reciprocity of learning between mentor and mentee and demonstrates the social exchange of skills and experiences that occur because of engaging in a peer mentoring relationship. Additionally, this definition helps communicate the role of our peer mentors as professional development coaches as well as aids in the formation of mentoring curriculum and programming.

Student development theory is also foundational within the ULN mentor model. For example, our team applies Schlossberg's Transition theory (1984) as a point of reference when developing programming. This theory informs our practice for how individuals experience significant transition (e.g. going to college). Specifically, Schlossberg's work identifies four components to examine during the transition cycle, which include situation, self, support, and strategies (Goodman, Schlossberg, \& Anderson, 2006). These components, known as the four S's, are informative when considering how success initiatives create programming to support successful transition and promote opportunities for students to examine and assess their individual situation, how they feel, what support and/or resources are available to them, and what strategies could them employ to ensure they successfully navigate the transition experience. ULN also draws on the work of foundational researchers in higher education who focus on student engagement and involvement in learning (Astin, 1977, 1984), academic and social integration (Pascarella \& Terenzini, 1977; Tinto, 1975), social support (Cobb, 1976, Pearson, 1990; Vaux et al., 1986), and developmental support (Chickering, 1969; Perry, 1970).

High quality mentor training is a critical component of the ULN mentor model. For practitioners in the field of peer mentoring and leadership, the best practice of providing consistent, ongoing, high-quality training is critical to success. Training equips the mentors and ensures mentees receive a consistent mentoring experience. The CRLA IMTPC certification model (CRLA, 2015) shapes the ULN peer mentor training model. The ULN program is working toward becoming a level-two CRLA-IMTPC-certified program and utilizes the requisite training standards. ULN peer mentor training includes two, day-long training sessions at the start of each semester in addition to on-going, one-hour weekly training sessions. The level-one (beginning level) mentor 
certification training model includes a total of 15 hours of professional development training. This level of certification covers seven required topics: "the role of the peer mentor; peer mentoring do's and don'ts; professional ethics for peer mentors; establishing rapport and motivating mentees; questioning and listening skills; preparing to study: organization, class analysis, and time management; campus and community resources." Additionally, ULN selects topics for eight hours of training, which can range from resilience, to becoming a change agent, creating a resume, or interview skills, to professional communication (CRLA, 2015). In addition to the up to 25 hours of training, peer mentors also require 50-75 hours of face-to-face mentoring experience. Returning mentors and lead mentors can receive additional levels of certification as they continue to acquire training and mentoring contact hours in subsequent years on the team.

Lastly, the ULN peer mentor model employs a system of tiered leadership (see figure 1). ULN students may apply to become a mentor after completing their first year in the program. Once a student becomes a mentor, they undergo training to facilitate weekly discussion sections on a team of two to three fellow mentors, supporting 18 to 24 first-year students in the ULN program. Mentors attend weekly training sessions facilitated by fellow Lead ULN mentors. Training sessions provide a consistent first-year experience, instill a greater awareness of the mentor's leadership style, and develop a capacity to work collaboratively toward a common goal. ULN mentors also meet weekly with their fellow small group mentors to plan how they will deliver training that provides first-year students time to apply and reflect on the week's leadership speaker series topic. Mentors also attend the first-year leadership speaker series, which provides positive role modeling and opportunity to set high expectations for first-year ULN students. Mentors then engage in activities during weekly mentor group discussions that align with the first-year leadership speaker series. Those topics include, but are not limited to: resilience, leadership and ethics, self-branding, growth vs. fixed mindset (Dweck, 2006), building successful teams, and developing a professional network.

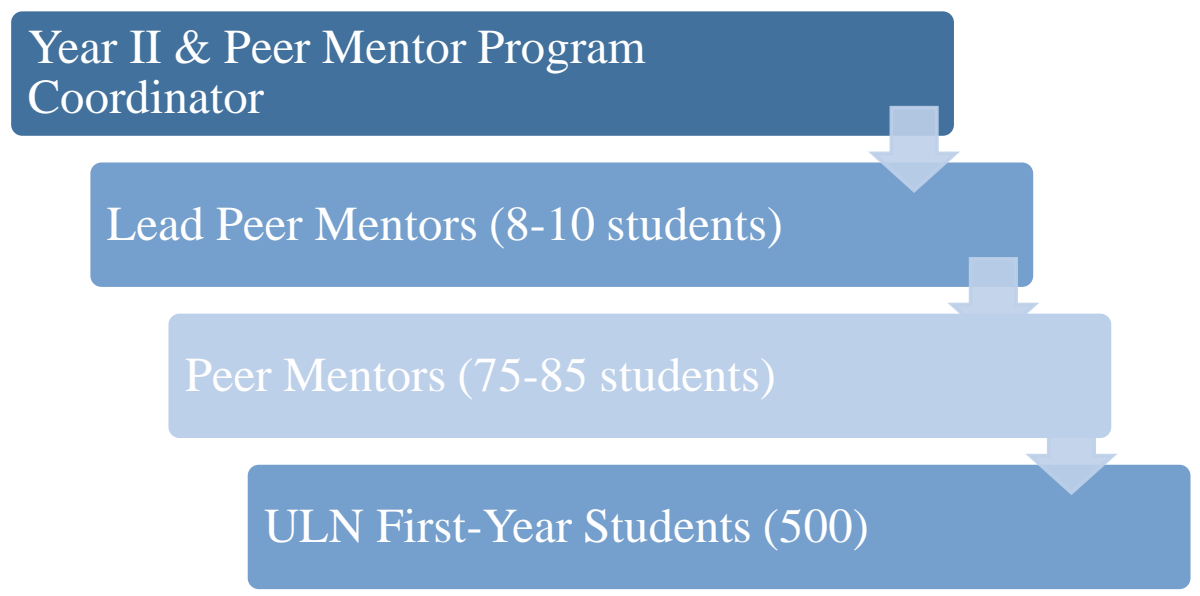

Figure 1. ULN Tiered Mentor Model

After completing one year as a mentor students have the opportunity to apply to become a lead mentor (8-10 positions available). Lead mentors are returning peer mentors who assume additional training to support the peer mentor coordinator (Year-two ULN Coordinator) and to learn to train their peers on the numerous training topics to deliver to the first-year ULN 
students. The Lead mentor training also takes place weekly. Serving as a mentor or lead mentor meets the program requirement of engaging in experiential learning. All ULN experiential learning opportunities give returning students a greater level of responsibility; therefore, lead mentors take on the added responsibility of mentoring a group of six to eight ULN peer mentors. Lead mentors facilitate weekly mentor-training sessions, support the coordinator, and assist staff at program events. Selection of lead mentors involves an interview process that identifies mentors who demonstrate a high level of maturity, creativity, problem solving skills, and discernment in handling challenging situations. Additionally, this year, the ULN mentor coordinator has two additional ULN interns who serve as liaisons to the peer mentor program. These are students who are interested in pursuing a career in higher education administration and whose primary role is to coordinate programming and communication between the first-year curriculum and the peer mentor programming.

\section{Why the comprehensive program model of ULN is successful}

The ULN program goes beyond traditional models of student success currently observed in higher education initiatives. The ULN model is comprehensive; it provides a four-year experience encompassing academic success through partnership with first-year academic communities, financial support in the form of a \$20,000 scholarship, peer mentoring and curriculum all presented through the lens of developing leadership and professional skills. Many institutions have stand-alone academic success programs, financial aid programs, and leadership and professional development programming.

The Student Success Initiatives unit within the Provost's Office at UT Austin has demonstrated that it is possible to bring together all of the components necessary to increase student success in the creation and implementation of the ULN program. Top leadership within the Provost's Office created an institutional imperative centered on student success and increased four-year graduation rates, paired with resources to support such efforts. UT Austin and the ULN program are making significant gains in the arena of student success. This section will provide student success outcome data for UT Austin and the ULN program, insight into program best practices and challenges, necessary components for program replication, and vision of ULN.

\section{UT Austin and ULN student success outcome data}

In 2011, the overall four-year graduation rate for UT Austin was 51\%, followed by a clear goal to reach $70 \%$ by the year 2017. As of fall 2016, the overall four-year undergraduate graduation rate has increased to a staggering 61\% (The University of Texas Statistical Handbook, 2016). UT Austin is on track to meet its goal because of the efforts of the Student Success Initiatives team, partnered with leadership from all colleges and schools, student affairs units, and the hard work and persistence of the undergraduate students themselves. Combined efforts such as providing expansion funds to existing academic communities and success programs, creating an innovative student help desk, and the ULN program, have all contributed to the overall goal of increasing retention and four-year graduation rates. Across seven academic communities and success programs supported by expansion funds, the first-year cohorts have an average persistence rate of $92.3 \%$ (returning for their sophomore year), compared to the overall UT persistence rate of 
95.1\%. The 2017 ULN cohort (returning for their senior year) is at 82.4\% persistence, in comparison to 85.2\% for the total UT 2017 cohort (SSI Internal Report, 2016).

Additionally, while many student-success efforts at The University of Texas at Austin have focused on keeping students on track to graduate by incentivizing behaviors consistent with timely progress, the University also recognizes the role of administrative barriers to reaching the goal of graduation. To help students who run into an administrative barrier to timely graduation, the Student Success Initiatives unit created the Graduation Help Desk. Staffed by a team in the Provost's Office, the Graduation Help Desk team works alongside students to resolve conflicts affecting their goal of graduating. This includes course availability issues, petitions for transferrable coursework and other obstacles that typically prevent students from graduating. More than 500 students have been assisted since the desk opened in spring 2014. In that time, those seeking help have branched out to also include faculty, academic advisors, and other campus staff searching for ways to helps students graduate on time.

The ULN program has led to substantial student success. The average SAT score across the 2017, 2018, and 2019 cohorts of ULN students is 1123 compared to 1295 of the general entering first-year SAT score for UT Austin. The average predicted four-year graduation rate for those ULN cohorts was $38.0 \%$ compared to $56.3 \%$ for entering first-year UT Austin students, which is a difference of 18.3 percentage points. Within the first three years, the ULN program demonstrates promising results in the areas of persistence and progress towards degree. For example, data gathered in the fall of 2016 showed 93.9\% persistence rate for the 2019 ULN cohort (returning after first year in college) in comparison to $95.1 \%$ for the general 2019 UT Austin class, a difference of just 1.2 percentage points. The 2018 ULN cohort returned for their third year at a rate of $85.9 \%$ in comparison to the general 2017 UT Austin class at $92.0 \%$, a difference of just 6.1 percentage points. Furthermore, ULN students show timely progress toward the completion of their degrees. Current ULN seniors starting their fourth year, the 2017 cohort, have passed 101 hours on average compared to 106 hours passed for the total UT Austin class of 2017. Current ULN juniors, the 2018 cohort, have passed 74 hours on average as they begin their third year, compared to 77 hours for the total 2018 cohort, an average difference of just one course. As a collective effort, the ULN program has brought together institutional, academic, financial, leadership and professional development resources to create an environment to close the student success gap at the University of Texas at Austin.

\section{ULN best practices and challenges}

As a newer program, it is imperative to engage in consistent formal and informal evaluation to gain feedback and create opportunity to identify best practices and identify challenges. The best practices and challenges for ULN fall into organized into three levels: student, organizational, and institutional. This section highlights those three levels and provides specific examples of best practices and challenges.

Student level. At the student level, ULN as a program has sought to bring resources together to provide a holistic four-year experience, create an environment of high support and challenge, and of role-modeling and encouraging the development of growth-mindset (Dweck, 2006). Teaching and encouraging a growth-mindset is a vital best practice within ULN. In particular, our 
programming and curriculum center on this concept, highlighting the idea that skills and abilities are not innate. With hard work, thoughtful practice, and individual reflection, you can greatly improve your skills and abilities in countless areas. Additionally, the program's curriculum has been informed by a collection of research brought together in Paul Tough's text (2012), How Children Succeed. This meta-analytic text brings together the importance of identifying and training on topics such non-cognitive skills (Heckman, 2001), grit (Duckworth \& Quinn, 2009), and motivation (Mischel, Shoda, \& Rodriguez, 1989). Staying current in research allows our programming to remain nimble to meet student needs. The training curriculum for ULN peer mentors centers on these major concepts and ideas, which leads to reinforcement of the messages and content presented in the leadership speaker series.

Students understand that the institution and program have high expectations for them. From day one in the program, students are recognized as leaders on our campus. The Senior Vice Provost, Dr. David Laude tells first-year students each year, "Look to your right, look to your left...you are looking at the leadership of the state of Texas.” Hearing this from such a high level of authority makes our students feel pride that they are a part of unique community, one that is preparing them for a lifetime of leadership and success both in and out of the classroom. ULN embraces the motto of "Leading from where you are.” This phrase encourages students to engage in leadership now. Leadership does not require a specific title, status, or age. There are always those above you, next to you, and behind you that are watching and waiting to see how you will lead. ULN students are not future leaders, they are leaders. ULN peer mentors bring this idea to life as they engage in leading as current students. They are actively taking advantage of training opportunities and time to interact with their mentees creating an environment where being a leader is natural, expected, and appreciated.

Just as best practices are important to acknowledge, an examination of challenges at the student level must also occur. Our greatest challenge arises in the large number of students ULN serves (up to 2,000). Tracking program requirements like attendance, community service hours and experiential learning (10 hours per week) is a considerable task. Each year, as the program has expanded to include a new class, our level of staffing and internal tools and systems have been pushed to their limits. For example, in year one (500 students total), taking attendance at the weekly leadership speaker series was initially addressed by using the i-clicker remote analytics tool. While the tool was effective, we were concerned about the student cost of purchasing the technology and cost for annual use. In the second year of the program, we utilized the expertise and local talent of biology professor Dr. Sarathi Sathasivan. Dr. Sathasivan and his team created the Squarecap mobile application, which we began using as our attendance and analytics tool. Through exploration of different types of analytics tools, we determined that Squarecap best met student needs and compatibly requirements to interface with our learning management system, Canvas. Although challenging in terms of learning new technology, Squarecap met the needs of our students (low cost, ease of use, and mobile access) and our organizational needs (high level of technical support, robustness of the tool, and accessing real time data) making it the best fit for our program. Additionally, feedback from our peer mentors was essential in gaining an understanding of the student perspective in utilizing these learning analytic tools as well. They were able to help us refine the use of these systems within the peer mentor weekly sessions as well as in regards to taking attendance and polling the group to check for understanding on content. 
Organizational level. At the organizational level, a key best practice for ULN lies in creating a staff model to meet student-success objectives set by the institution in addition to meeting the needs of students served within the program. With great intention, the organizational structure of ULN was created with specific positions with clearly defined roles and responsibilities. Our current organizational structure includes a director, an experiential learning program manager, four cohort coordinators (one professional: 500 students), an administrative associate, and one graduate research assistant. The program model introduces the idea, and supports the benefits, of having multiple mentors (informal and formal). As students enter the program they work with our first-year coordinator, and as they transition from year to year, they work with a new coordinator trained to meet the needs of second-, third-, or fourth-year students. Therefore, at the end of a student's time in ULN, their professional network will include four cohort coordinators, peer mentors, campus partner supervisors, and other experiential learning supervisors. Staff and student thrive in the work environment, due to the careful creation of specific roles, with clear directives and boundaries. In regards to the human resources perspective, this simplifies the hiring process and helps the selection committee zero in on the job requirements and the skills, talents, and abilities needed to meet those job requirements

As a team, the staff also engages in quarterly (at a minimum) team workdays held outside of the office (on or off-campus location) to focus on finding solutions to challenges facing our students, staff, or organization. These workdays also support an environment of problem-solving, opendialogue, vulnerability, trust, and critical thinking. They also provide time to engage in teambuilding activities that further challenge and support the growth of our organization at the team level. Providing opportunity for meaningful professional development (attending/presenting at conferences, engaging in workshops, etc.) is also essential to maintaining a team dynamic and providing opportunities for on-going learning that will further equip staff in their roles. Peer mentors also experience the importance of taking time to train, prepare, and to spend time team building. At the beginning of each semester, peer mentors attend an interactive day of training facilitated by the ULN staff and Lead mentors. This training focuses on reminding peers of their critical role in ULN, preparing them with training and tools to be successful, and creating deeper bonds within the peer mentor community.

The most prevalent challenge faced at the organizational level centers on staffing capacity and staff care. One challenge is found in the large number of students to each cohort coordinator. Ideally, the cohort coordinators would know their students well. However, within the span of an academic year it is not physically possible to meet individually with each student, in addition to completing other job duties. Coordinators are comparable to case managers in many ways. They are professionals trained to operate in triage mode. When coordinators meet with a student, they utilize active listening training to target identifiable problems (typically nonacademic challenges affecting academic performance) and to recommend resources to meet those surface-level issues. Then, they continue a line of questioning to identify what might be at the root of these surfacelevel issues (e.g. missing class, depression, poor time management). Our coordinators are not trained counselors; however, because they have built a rapport with students, they are able to create a space in which students share major life challenges/experiences they are facing (e.g. sexual assault, mental-health issues, depression, anxiety, family financial stress, etc.). Furthermore, that shared trust between the student and coordinator allows our team to assess all 
of the issues presented and to connect students with staff and resources on campus that will get them back on track academically and personally. Often times, our peer mentors are our first line of defense. Because of the frequency with which peer mentors interact with first-year students, they are the first to notice trends and changes in student engagement. Peer mentor training instructs them to notify their lead mentors and/or peer mentor coordinator of such changes, which leads to faster connection to resources and help for the student. Moreover, these interactions are necessary, valuable, and intense. It is important to ensure that staff members and peer mentors have access to resources to de-stress, share challenges they are facing, and to know when to ask for guidance when working with a particularly difficult student situation. This environment is created for our peer mentors in their weekly mentor training sessions.

Institutional level. It is only through institutional support and organization that ULN as a program went from a vision to implemented reality. At the institutional level, through structures within the influential leadership and resources provided by the Provost's Office and the Graduation Rate Champion, ULN as an incentive-based scholarship program is able to bring together units from across campus to provide a four-year experience that results in student success. ULN depends on collaboration from many areas in order to function: Student Success Initiatives in the Provost's Office, academic and success programs, leadership from all colleges and schools, the Office of Admissions, the Office of Financial Aid, Development, the Division of Diversity and Community Engagement, the Study Abroad Office, Undergraduate Research, as well as over 250 campus partners who supervise hundreds of ULN on-campus interns, and offcampus partners. Through the leadership of the Provost's Office, all of these constituents have come together to collectively meet the institutional goal of a $70 \%$ four-year graduation rate at UT Austin. The foundational belief that student success is of critical importance to the mission of the institution, and having that belief voiced and supported by the platform of the Provost's Office has been critical to our success as a program.

Collaboration across departments and units is essential in meeting major student success goals. The directors of all of the academic communities and success programs who received expansion funds from Student Success Initiatives, the director of ULN, and the associate vice provost for student success, all meet weekly to communicate and collaborate. As a team, this group works to ensure smooth recruitment and placement of incoming students in academic communities and success programs, coordinate programming in an effort to prevent program overlap and content redundancy, and discuss current student issues and how their programs can address those challenges or bring attention to them. This collaboration results in everyone knowing how each program works and the populations they serve. It also creates a shared network of professionals, who work together to ensure that no students fall through the cracks. UT Austin is a decentralized campus; however, when it comes to student success they are leading the way by collaborating across units to create an environment conducive to producing student success.

Challenges at the institutional level include establishing permanent funding for ULN. With recurring costs of up to $\$ 10$ million in scholarship dollars, creating and maintaining varying streams of funding is critical. As discussed previously, ULN scholarship dollars are currently funded through tuition set-aside, significant gifts like the Houston Endowment, and some permanently endowed funds. The external relations team within Student Success Initiatives is 
working diligently to explore and create new sources of funding for programs like ULN as well as academic communities and success programs.

\section{Replication and future vision for the program}

As ULN is now a four-year, fully staffed program with demonstrated success, the question of replication is commonly asked as representatives from other institutions visit UT Austin to learn more about this innovative model. ULN was created to function at a large, public, tier-one research university; however, the ULN program model could be tailored to meet the needs of a variety of institutional types (private/public, research/teaching, etc.) as long as a core group of program components are maintained.

First, replication of the ULN model can only be successful at institutions that demonstrate a clear commitment to student success and increasing four-year graduation rates, specifically for diverse student populations. Second, a commitment to collaborative leadership across units, colleges, programs, etc. is essential to implementing the ULN model. This model relies on collaboration at the executive administrative level (president, provost, deans) in addition to the programmatic level (program directors, service unit directors, diversity unit, etc.). For successful implementation to occur, the institution must gather its key leadership and come together to create a comprehensive student success plan.

As mentioned above, the ULN model at UT Austin was not intended for exact replication; however, the core components of the model that should remain intact aside from institutional and leadership commitment include:

- Student financial support over four years (scholarship),

- Focus on four-year graduation,

- First-year academic support (provided through academic communities and success programs or initiatives),

- Intensive first-year leadership and professional training with ongoing training opportunities in the second- through fourth-years,

- Second-year on-campus internship opportunities,

- Service component,

- Mechanism for self-reflection over four years, and

- Institutional data analysis support.

ULN as a team is working to create clear outlines for the program structure, components, curricula, and resources required for implementation. These resources will be useful in engaging with institutions wishing to create a ULN-like program to increase student success on their campuses.

As a comprehensive program model, ULN is moving the needle of student success at the University of Texas at Austin. ULN is remarkably unique with a vast array of invested stakeholders: university leadership, students, staff, faculty, and campus and community partners. This broad collaboration results in the most extraordinary collective effort to create a shared sense of community and commitment to undergraduate student success. ULN demonstrates how highly trained undergraduate peer mentors are critical. They extend the organization's ability to 
meet and identify student needs, create community, and deliver important content leading to leadership and professional development for first-year students. Additionally, peer mentors gain valuable transferrable skills because of their experience, which increases their post-baccalaureate marketability in regards to entering the workforce or graduate and/or professional school arena.

ULN is thriving, entering new territory as it prepares fourth-year students for graduation and their path beyond the University of Texas at Austin. The "Network" of ULN is being constructed as we graduate our first class and continue to build relationships with partners in industry, graduate and professional schools, and service paths like the Peace Corps and Teach for America. This innovative and holistic approach to student success is working, and we look forward to seeing our students and alumni thrive, as well as partnering with other institutions who are committed to innovative approaches to student success. 


\section{References}

Astin, A. W. (1977). Four critical years: Effects of college on beliefs, attitudes, and knowledge. San Francisco, CA: Jossey-Bass.

Astin, A. W. (1984). Student involvement: A developmental theory for higher education. Journal of College Student Personnel, 297-308. Retrieved from

http://www.ydae.purdue.edu/lct/hbcu/documents/Student_Involvement_A_Developmental_Theo ry_for_HE_Astin.pdf

Astin, A. W. (1993). What matters in college: Four critical years revisited. San Francisco, CA: Jossey-Bass.

Allen, W. R. (1985). Black student white campus: Structural, interpersonal, and psychological correlates of success. Journal of Negro Students, 54(2), 134-137.

https://doi.org/10.2307/2294928

Allen, W. R. (1992). The color of success: African-American college student outcomes at predominantly white and historically Black public colleges and universities. Harvard Educational Review, 62, 26-44. https://doi.org/10.17763/haer.62.1.wv5627665007v701

Baum, S., Ma, J., \& Payea, K. (2013). Education pays 2013. The College Board.

Carnegie Foundation. (2014). Institution profile: The University of Texas at Austin. Retrieved from http://carnegieclassifications.iu.edu/lookup/lookup.php

Chickering, A. W. (1969). Education and identity. San Francisco, CA: Jossey-Bass.

Cigarroa, F. (2011). A framework for advancing excellence through the University of Texas System. As presented at the meeting of the Board of Regents, May 12, 2011. Retrieved from http://www.as.utexas.edu/bov/resources/05.Cigarroa-advancing_excellence_may2011.pdf

Cobb, S. (1976). Social support as a moderator of life stress. Psychosomatic Medicine, 38(5), 300-314. Retrieved from http://www.psychosomaticmedicine.org/content/38/5/300.full.pdf+html https://doi.org/10.1097/00006842-197609000-00003

Cokely, K. (2000). An investigation of academic self-concept and its relationship to academic achievement in African American college students. Journal of Black Psychology, 26(2), 148164. https://doi.org/10.1177/0095798400026002002

Coles, A. (2011). The Role of Mentoring in College Access and Success. Research to Practice Brief. Institute for Higher Education Policy.

College Reading and Learning Association. (2015). International Mentor Training Program Certification. Retrieved from: http://www.crla.net/index.php/certifications/imtpc-internationalmentor-training-program 
Cuyjet, M. J. (1997). African American Men on College Campuses: Their Needs and Their Perceptions. New Directions for Student Services, 1997: 5-16. https://doi.org/10.1002/ss.8001

Dahlvig, J. (2010). Mentoring of African American Students at predominantly white institutions (PWI). Christian Higher Education, 9(5), 369-395. https://doi.org/10.1080/15363750903404266

Dweck, C.(2006). Mindset: The new psychology of success. New York, NY: Ballantine Books.

Duckworth, A., Quinn, P. (2009). Development and Validation of the short grit scale (Grit-S). Journal of Personality Assessment, 91(2) https://doi.org/10.1080/00223890802634290

Engle, J., \& Tinto, V. (2008, November). Moving beyond access: College student success for low-income, first-generation students. Retrieved from Pell Institute for the Study of Opportunity in Higher Education website: http://files.eric.ed.gov/fulltext/ED504448.pdf

Flowers, L. \& Pascarella, E. T. (1999). The effects of college racial composition on African American college students' orientations toward learning for self-understanding. Professional Educator, 22(1), 22-47.

Fleming, J. (1984). Blacks in college: A comparative study of students' success in Black and in White institutions. San Francisco: Jossey-Bass.

Fry, R. (2011). Hispanic college enrollment spikes, narrowing gaps with other groups: 24\% growth from 2009 to 2010. Pew Research Center, (August), 1-29. Retrieved from www.pewhispanic.org.

Goodman, J., Schlossberg, N. K., \& Anderson, M. L. (2006). Counseling adults in transition (3rd ed.).New York, NY: Springer Publishing Company, Inc.

Hansen, R.N. \& Johnston, M.C. (1986, September). College students as paraprofessional career specialists. Journal of Career Development, 13(1), 18-29.

https://doi.org/10.1177/089484538601300103

Harris, V. (2012). The effectiveness of African American and Hispanic mentoring programs at predominantly white institutions. Center for Higher Education, Working paper series, Ohio University, 1-15.

Heckman, J. \& Rubinstein, Y. (2001 May). The importance of non-cognitive skills: Lessons from the GED testing program. American Economic Review, 91(2), (May, 2001). https://doi.org/10.1257/aer.91.2.145

Kram, K., \& Isabella, L. (1985). Mentoring alternatives: The role of peer relationships in career development. Academy of Management Journal, 28(1), 110-132. https://doi.org/10.2307/256064 
Mischel, W., Shoda, Y., \& Rodriguez, M. (1989). Delay of gratification in children. Science, 244( 4907), 933-938. https://doi.org/10.1126/science.2658056

Moore, K. M., \& Amey, M. J. (1988, Winter). Some faculty leaders are born women. New Directions for Student Services, 1998(44), 39-50. https://doi.org/10.1002/ss.37119884406

National Center for Education Statistics. Integrated Postsecondary Education Data System (IPEDS). Retrieved from: http://nces.ed.gov/

Pascarella, E. T., \& Terenzini, P. T. (1977). Patterns of student-faculty information interaction beyond the classroom and voluntary freshman attrition. Journal of Higher Education, 48(5), 540552. https://doi.org/10.2307/1981596

Pearson, R.E. (1990). Counseling and social support: Perspectives and practice. Newbury Park, CA: Sage Publications.

Perry, W. G. (1970). Forms of intellectual and ethical development in the college years. New York, NY: Holt, Rhinehart, and Winston.

Schlossberg, N. K. (1984). Counseling adults in transition. New York, NY: Springer publishing company.

Sipe, C.L. (1996). Mentoring: A Synthesis of P/PV’s Research: 1988-1995.

Smith, J.L. (2014). Undergraduate peer mentors serving underrepresented students at a predominantly white institution (Doctoral dissertation).

Strayhorn, T. L., \& Terrell, M. C. (2010). The evolving challenges of Black college students new insights for policy, practice, and research. (1 ed., pp. 1-4). Sterling, VA: Stylus Publishing, LLC.

Thomsen, J. (2015). Search for Success. Inside Higher Ed. Retrieved from https://www.insidehighered.com/news/2015/08/10/officials-11-partnering-universities-sharestrategies-helping-students-graduate

The University of Texas at Austin. (2016). Statistical Handbook: Student characteristics: Fall 2016. Retrieved from http://reports.utexas.edu/statistical-handbook.

The University of Texas at Austin. (2015). Statistical Handbook: Student characteristics: Fall 2015. Retrieved from https://sps.austin.utexas.edu/sites/ut/IRRIS/Pages/Stat-Handbook.aspx

The White House Office of the Press Secretary. (2009). Remarks at Macomb Community College in Warren, Michigan. Compilation of Presidential Documents. Washington, DC: Office of the Federal Register. Retrieved from https://www.gpo.gov/fdsys/pkg/DCPD200900565/pdf/DCPD-200900565.pdf 
Tinto, V. (1975). Dropout from higher education: A theoretical synthesis of recent research. Review of Educational Research, 45(1), 89-125. https://doi.org/10.3102/00346543045001089

Tough, P. (2012). How children succeed. New York, NY: Houghton Mifflin Harcourt Publishing Company.

Tough, P. (2014). Who gets to graduate, New York Times. Retrieved from https://www.cfa.harvard.edu/cfawis/new_york_times.pdf

PBS Newshour (2015, August 7). Why Poor Students Drop Out Even When Financial Aid Covers The Cost. Retrieved from http://www.pbs.org/newshour/bb/poor-students-drop-evenfinancial-aid-covers-cost/

U.S. News and World Report. (2016). Best colleges in 2015. Retrieved from http://colleges.usnews.rankingsandreviews.com/best-colleges/rankings/national-universities

UT News. (2012). Graduation Rate Champion Appointed at The University of Texas at Austin [Press release]. Retrieved from http://news.utexas.edu/2012/05/08/graduation_rate_champion

Vaux, A., Phillips, J., Holly, L., Thomson, B., Williams, D., \& Stewart, D. (1986). The social support appraisals (SS-A) scale: Studies of reliability and validity. American Journal of Community Psychology, 14(2), 195-219. https://doi.org/10.1007/BF00911821

Walpole, M. (2003). Socioeconomic status and college: How SES affects college experiences and outcomes. The Review of Higher Education, 27(1), Fall, 45-73.

https://doi.org/10.1353/rhe.2003.0044 


\section{Author information}

Jennifer Smith serves as the Director of the University Leadership Network (ULN) at The University of Texas at Austin. As part of the university's Student Success Initiatives (SSI) unit, ULN was created to increase four-year graduation rates. She was appointed to provide a unique student experience based on leadership, professional development, and experiential learning combined with the opportunity to earn a significant scholarship. Jennifer was instrumental in the development and implementation of a number student success initiatives at UT Austin, including the University Leadership Network, the Texas Interdisciplinary Plan Mentor Academy, and the College of Natural Sciences Peer Leader Academy. Dr. Smith received both her Master of Educational Administration and Doctor of Educational Administration from the University of Texas at Austin. Jennifer's research and practice center on leadership, incentive-based scholarships, undergraduate peer mentoring, and the experiences of underrepresented undergraduate populations.

Jennifer L. Smith, PhD

Student Success Initiatives

The University of Texas at Austin

Flawn Academic Center (FAC 334)

2304 Whitis Avenues

Austin, TX 78712

E-mail: jlsmith@austin.utexas.edu

Fax: 512-232-2800 